\title{
Reaproveitamento do caroço da azeitona para produção de sabonete esfoliante: Uma produção sustentável
}

\author{
Reuse of stone olive for production exfoliating soap: A sustainable production \\ Raquel Êmily Pinheiro Cordeiro' ${ }^{1}$, Leilson de Oliveira Ribeiroº ${ }^{2}$ Wilson Chimatti ${ }^{3}$, Marisa Fernandes \\ Mendes $^{4}$, Cristiane de Souza Siqueira Pereira ${ }^{5}$.
}

\begin{abstract}
Resumo
Inúmeras indústrias de cosméticos têm direcionado suas pesquisas no desenvolvimento de novos produtos utilizando matérias-primas de origens vegetais, representando uma alternativa de substituição dos materiais sintéticos por naturais. Uma tendência evidenciada ultimamente é a utilização de resíduos do processamento de alimentos tais como sementes e cascas, devido o grande potencial dos componentes bioativos dos mesmos. O uso do caroço de azeitona na área cosmética apresenta características favoráveis devido à qualidade dos mesmos ajudar na esfoliação da pele. O caroço da azeitona constitui um dos principais resíduos gerados nas indústrias de processamento de azeite. Atualmente estes resíduos são geralmente queimados, a fim de recuperar o calor residual da sua combustão. Devido as suas substâncias químicas e físicas, o caroço é rico em componentes bioativos para sua utilização ser restringida apenas a processos de combustão. Diante do exposto o objetivo deste trabalho foi produzir um sabonete esfoliante em barra à base de caroço de azeitona, agregando valor a este resíduo.

Palavras-Chave: Sabonete. Resíduo. Azeitona. Cosméticos.
\end{abstract}

\begin{abstract}
Numerous cosmetic industries have directed their research to develop new products using raw materials of plant origin, representing a possible replacement for natural synthetic materials. Demonstrated a trend recently is to use wastes from food processing such as seeds and peel because of the great potential of these bioactive components. The use of olive stone in the cosmetics area has favorable characteristics due to the quality of these help in exfoliating the skin. The core of the olive is a major residue generated in the process industries of oil. Currently these residues are usually burned to recover waste heat of its combustion. Due to its chemical and physical, the core is rich in bioactive components for its use to be restricted only to combustion processes. Given the above the aim of this work was to produce an exfoliating soap bars based on olive pit, adding value to this residue. Keywords: Soap. Residue. Olive cosmetics.
\end{abstract}

\section{Introdução}

A busca constante da manutenção por uma aparência jovem tem favorecido, cada vez mais, o desenvolvimento da indústria de cosméticos no Brasil e no mundo. Esse rápido crescimento é resultado de fatores como o aumento da expectativa de vida da população, participação ativa da mulher no mercado de trabalho e outros (Maia, 2002).

De acordo com a Agência Nacional de Vigilância Sanitária (ANVISA) produtos de higiene pessoal, cosméticos e perfumes são preparações constituídas por substâncias naturais ou sintéticas, de uso externo nas diversas partes do corpo humano, como pele, sistema capilar, unhas, lábios, órgãos genitais externos, dentes e membranas mucosas da cavidade oral, e tem como objetivos principais limpá-los, perfumá-los, alterar sua aparência, corrigir odores corporais e protegê-los ou mantê-los em bom estado.
Segundo a Resolução no 211 (2005) da ANVISA, os sabonetes são produtos de higiene pessoal e podem ser classificados em grau I ou II. Esta classificação indica o nível de risco de efeitos adversos que cada tipo de produto pode oferecer, considerando sua formulação, finalidade e modo de uso. Na categoria de grau I estão classificados os sabonetes abrasivos ou esfoliantes mecânicos, faciais ou corporais, e os desodorantes. Esses produtos oferecem um risco mínimo no seu uso. Já a categoria de grau II abrange os sabonetes antissépticos, infantis e de uso íntimo.

A cosmetologia vive o que se denomina de "onda verde". Uma tendência que abrange a indústria cosmética mundial (Oliveira 2003). Inúmeras indústrias de cosméticos buscam a inovação, utilizandose de matérias-primas de origens diversificadas, principalmente oriundas de vegetais, representando uma alternativa de substituição de materiais sintéticos por naturais (Souza e Ferreira, 2010).

1. Universidade Severino Sombra, Curso de Química Industrial, Vassouras-RJ, Brasil.

2. Universidade Federal do Rio de Janeiro, Escola de Química, Rio de Janeiro-RJ, Brasil.

3. Universidade Severino Sombra, Químico Industrial, Vassouras-RJ, Brasil.

4. Universidade Federal Rural do Rio de Janeiro, Curso de Engenharia Química, Rio de Janeiro-RJ, Brasil.

5. Universidade Severino Sombra, Vassouras-RJ, Brasil. 
De acordo com Novak et al (2014) uma nova classe de produtos de higiene pessoal denominados biocosméticos tem surgido através de novas tecnologias, considerando-se o conceito de desenvolvimento sustentável, tais como a nano e biotecnologia. Para os autores esta classe de produtos utilizando-se uma variedade de resíduos industriais como matérias-primas, gera produtos de alto valor agregado, além de remover uma grande quantidade de poluentes do ambiente.

$\mathrm{O}$ uso de óleos e extratos vegetais provenientes principalmente da grande biodiversidade brasileira também tem sido fonte de pesquisas de muitas indústrias. $\mathrm{O}$ azeite de oliva misturado em composições cosméticas pode atuar como antioxidante por ser rico em vitaminas A, D, K e E e por ser rico em ácido oleico, apresentando características não só como hidratante, mas como um retardador do envelhecimento cutâneo. O óleo tem propriedades capazes de aumentar a elasticidade, diminuir o ressecamento e regenerar a pele (EPAMIG, 2013).

A esfoliação é uma técnica na qual as células mortas são removidas da superfície da pele promovendo uma aparência mais jovem e saudável. Vários compostos são conhecidos por serem úteis como esfoliantes como quartzo, grãos moídos, peeling químicos conhecidos como alfa e beta hidroxiácidos, ácidos retinóico (Mohammadi et al 2005). De acordo com estes autores é necessária uma variedade de alternativas para a esfoliação para atender diversas necessidades, pois os tipos de pele variam entre os consumidores. Na utilização de produtos de origem vegetal com características esfoliantes, destacam-se os bagaços da uva, sementes de maracujá, aveia, arroz, semente de damasco e linhaça.

$\mathrm{O}$ uso do caroço de azeitona na área cosmética apresenta características favoráveis devido à qualidade dos mesmos ajudar na esfoliação da pele. Constitui um dos principais resíduos gerados nas indústrias de processamento de azeite. Atualmente estes resíduos são geralmente queimados, a fim de recuperar o calor residual da sua combustão. Apesar dos benefícios ambientais da utilização desta biomassa como combustível, persistem alguns problemas, como a poluição do ar causada pela emissão de monóxido de carbono, óxidos de nitrogênio e partículas, tais como fuligem e cinzas produzidas pela combustão (Rodríguez et al, 2008)

De acordo com Rodríguez et al (2008) o caroço da oliva é um material lignocelulósico, com a hemicelulose, celulose e lignina, como componentes principais. Devido as suas substâncias químicas, o caroço é rico em componentes bioativos como polifenóis para sua utilização ser restringida apenas a processos de combustão. Diante do exposto o objetivo deste trabalho foi desenvolver um sabonete esfoliante em barra à base de caroço de azeitona, agregando valor a este resíduo.

\section{Material e Métodos}

\section{Material}

Componentes do sabonete: base glicerinada branca, óleo de oliva, caroço de azeitona moído, BHT, metilparabeno, propilparabeno, glicerina, corante, essência. Todos os produtos foram adquiridos comercialmente de diferentes fornecedores. $\mathrm{O}$ caroço de azeitona e o óleo de oliva foram gentilmente cedidos pela Indústria Antares Alimentos. O caroço é obtido após o processo de descaroçamento das azeitonas de mesa e corresponde a maior parte dos resíduos gerados pela empresa. O caroço foi triturado em moinho de discos, de granulometria 1,18 mm na Embrapa Solos.

\section{Preparo da formulação}

Foram desenvolvidas várias propostas de formulações de sabonete em barra, onde diferentes concentrações de caroço de azeitona moído e óleo de oliva foram testados. A formulação final desenvolvida é descrita na Tabela 1.

Tabela 1. Formulação de sabonete em barra com óleo de azeitona e pó da semente de azeitona.

\begin{tabular}{cc}
\hline Base Glicerinada Branca & $90 \%$ \\
\hline Óleo de oliva & $1,0 \%$ \\
\hline Metilparabeno & $0,10 \%$ \\
\hline Propilparabeno & $0,10 \%$ \\
\hline BHT & $0,10 \%$ \\
\hline Glicerina & $5 \%$ \\
\hline Caroço azeitona moído & $2 \%$ \\
\hline Corante & q.s \\
Essência & $2 \%$ \\
\hline
\end{tabular}

\section{Modo de preparo}

A técnica de preparo utilizada para obtenção do sabonete em barra foi através da pesagem da base glicerinada transparente finamente cortada e fundida em banho-maria, com controle de temperatura $\left(60{ }^{\circ} \mathrm{C}\right)$. Após diminuição da temperatura $\left(40{ }^{\circ} \mathrm{C}\right)$ acrescentou-se metilparabeno, propilparabeno e o BHT, homogeneizando-se suavemente. Em seguida, foi adicionado $1 \%$ do óleo de oliva e $2 \%$ do caroço de azeitona moído, previamente dissolvido em glicerina. Após esta etapa acrescentou - se o corante e essência. $\mathrm{O} \mathrm{pH}$ foi analisado e corrigido utilizando acido cítrico. Verteu - se o conteúdo para o molde previamente limpo com álcool $70 \%$, que posteriormente foi solidificado em temperatura ambiente. 
A maioria dos sabonetes artesanais fabricados com óleo de oliva não possui o aroma da oliva, mas uma mistura de essências como capim limão e essências amadeiradas. No presente trabalho diferentes essências foram utilizadas como: essência de oliva; essência de capim limão e essência de pitanga. Foi testada também uma mistura da essência de oliva com a essência de capim limão.

\section{Testes físico-químicos de controle de qualidade do sabonete}

\section{Teste de Absorção e Resistência à Água}

Mergulhou se um tablete do sabonete em $250 \mathrm{~mL}$ de água por 24 horas. Pesaram-se os tabletes secos e molhados, após a retirada da matéria mole. Os testes foram realizados em duplicata (Silva, 2003).

\section{Teste de Durabilidade}

Mergulhou se um tablete do sabonete em $75 \mathrm{~mL}$ de água por 5 horas. Pesaram-se os tabletes secos e molhados, após a retirada da matéria mole. Os testes foram realizados em duplicata (Silva, 2003).

\section{Teste de Rachadura}

Mergulhou se um tablete do sabonete em banho de água por 10 minutos. Analisou-se os tipos de rachadura na superfície por um período de 7 dias. Os testes foram realizados em duplicata (Silva, 2003).

\section{Altura de Espuma}

$2 \mathrm{~g}$ do sabonete foram pesados e transferidos para uma proveta de $100 \mathrm{~mL}$, adicionado em seguida 18 $\mathrm{mL}$ de água. Agitou se vigorosamente até a formação de espuma. Essa solução foi mantida em repouso por 10 minutos. Anotou se o volume de espuma obtida na proveta. Os testes foram realizados em duplicata. (Prista et al., 1995).

\section{Índice de Saponificação}

$2 \mathrm{~g}$ do sabonete com o óleo foram adicionados, em um balão de $250 \mathrm{~mL}$. Em seguida, foram adicionados $25 \mathrm{~mL}$ de hidróxido de potássio alcoólico $4 \%$. O sistema de refluxo foi montado com agitação e aquecimento em banho-maria em ebulição por 30 minutos e na sequencia foi acrescentado $1 \mathrm{~mL}$ de fenolftaleína alcoólica $1 \%$ e titulou-se a solução com ácido clorídrico $0,5 \mathrm{~N}$. O mesmo procedimento foi realizado utilizando o sabonete base. Repetiu- se a operação sem a presença de sabonete e o volume de acido clorídrico $0,5 \mathrm{~N}$ necessário para a neutralização foi anotado (Farmacopéia Brasileira, 2010). O índice de saponificação foi calculado através seguinte fórmula:

Índice de Saponificação = 28,05(n1-n2) $/ \mathrm{m}$ onde:

$\mathrm{n} 2=$ volume em $\mathrm{mL}$ de acido clorídrico para titular a amostra;

$\mathrm{n} 1=$ volume em $\mathrm{mL}$ de acido clorídrico para neutralização do hidróxido de potássio alcoólico 4\%. $\mathrm{m}=$ massa de amostra em gramas.

\section{Índice de Acidez}

Em um erlenmeyer de $250 \mathrm{~mL}$ foi adicionado $10 \mathrm{~g}$ do sabonete com o óleo. Adicionou-se $50 \mathrm{~mL}$ de mistura de volumes iguais de etanol $95 \%$ e éter. Foi adicionado $1 \mathrm{~mL}$ de fenolftaleína alcoólica $1 \%$ e em seguida titulou-se com hidróxido de potássio $0,1 \mathrm{~N}$, agitando-se constantemente, até obtenção de coloração rosada persistente por 15 segundos (Farmacopéia Brasileira, 2010). O índice de acidez foi calculado através a seguinte fórmula:

Índice de Acidez $=5,610 \mathrm{n} / \mathrm{m}$

onde:

$\mathrm{n}=$ volume em $\mathrm{mL}$ de hidróxido de potássio alcoólico $0,1 \mathrm{~N}$ utilizada.

$\mathrm{m}=$ massa de amostra em gramas.

\section{Determinação do $\mathrm{pH}$}

$\mathrm{O}$ pH foi determinado, pelo método potenciométrico, através da diluição de $10 \mathrm{~g}$ do sabonete em $100 \mathrm{~mL}$ de água destilada com auxilio de uma barra magnética para facilitar a solubilização da amostra (Farmacopéia Brasileira, 2010).

\section{Análise Sensorial}

As amostras foram analisadas, levando-se em consideração as propriedades organolépticas, através do olfato. Os métodos afetivos representam a opinião do consumidor e avalia o quanto o consumidor gosta ou desgosta do produto. O ensaio de preferência é conhecido como pareado-preferência e é realizado para que o painelista assinale, entre diferentes amostras, aquela de sua preferência.

A análise sensorial foi realizada no laboratório de Química da Universidade Severino Sombra. Preparouse um lote do sabonete sem fragrância e um lote do sabonete com as fragrâncias: oliva; capim limão, pitanga. Foi testada também uma mistura da essência de oliva com a essência de capim limão. As amostras foram 
codificadas com número de três dígitos, escolhidos ao acaso, de forma a não influenciar os provadores.

\section{Resultados e Discussões}

A Figura 1 ilustra o sabonete em barra desenvolvido com o co-produto do processamento das azeitonas de mesa.

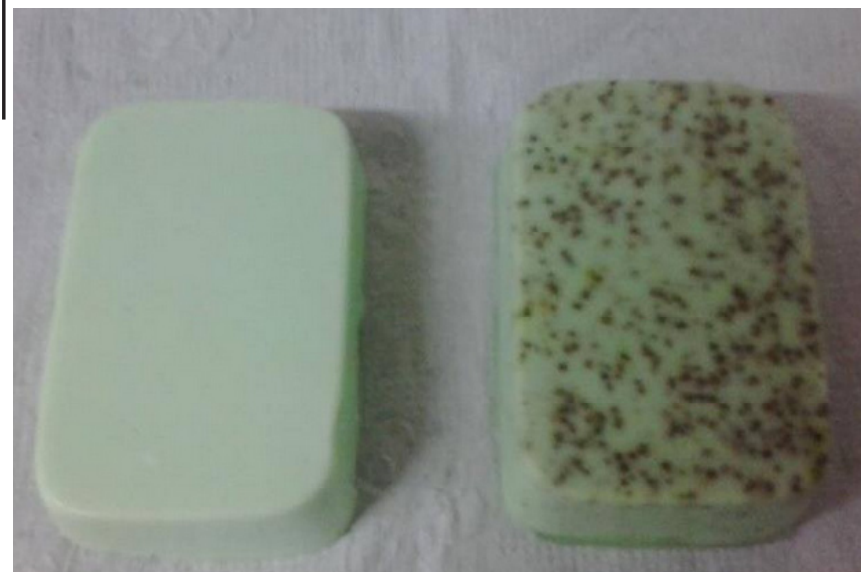

Figura 1. a) base glicerinada; b) sabonete esfoliante

Foram realizados testes físico-químicos de qualidade do sabonete de acordo com as Tabelas 2 e 3.

No teste de absorção e resistência à água, foram utilizadas amostras do sabonete com o óleo e caroço moído incorporado, e amostras da base glicerinada transparente sem adição de qualquer componente. De acordo com os resultados obtidos verificou-se que o sabonete apresentou uma menor absorção de água em comparação à base glicerinada, apresentando maior resistência à água Os óleos vegetais são substâncias formadas por cadeias longas de carbono e hidrogênio aumentando assim a sua hidrofobicidade e em consequência disto a não absorção de água.

Semelhante ao do teste de absorção e resistência a água, comparando-se o sabonete formulado e a base glicerina verificou-se que o sabonete apresentou maior durabilidade por absorver menos água, já que a quantidade de água absorvida pela base foi maior que a absorvida pelo sabonete.

Quanto à altura de espuma, observou-se uma redução da mesma no sabonete em comparação a base glicerinada. Essa redução pode ser devido à adição do óleo e não utilização de compostos tensoativos na formulação. Os tensoativos são substâncias capazes de emulsionar, estabilizando uma emulsão e formar espuma, pela tensão interfacial entre o líquido e o ar (ARNAU, 1995).

Quanto ao teste de rachaduras, verificou-se que ambas as amostras analisadas não apresentaram rachaduras.

A Tabela 3 apresenta os resultados das analises de saponificação e acidez.

Tabela 3: Testes físico-químicos de controle de qualidade do sabonete

$\begin{array}{cc}\text { Composições } & \begin{array}{c}\text { Índice saponifica- } \\ \text { ção } \\ (\mathrm{mg} \mathrm{KOH} / \mathrm{g})\end{array}\end{array}$

\begin{tabular}{lcc} 
Sabonete & 9,82 & 1,52 \\
Base glicerinada & 15,43 & 1,01 \\
\hline
\end{tabular}

Obteve-se como índice de saponificação do sabonete o valor de $9,82(\mathrm{mg} \mathrm{KOH} / \mathrm{g})$ e para a base glicerinada um valor de 15,43 (mg KOH/g). Como o valor do índice de saponificação é inversamente proporcional ao peso molecular médio dos ácidos graxos, pode-se concluir que o sabonete possui uma quantidade maior de ácidos graxos em comparação a base glicerinada, devido à adição do óleo de oliva na formulação do sabonete.

O parâmetro de acidez está diretamente relacionado com a natureza e qualidade da matériaprima (fruto ou semente), com a qualidade e o grau de pureza do lipídeo e com o processamento. Após análises o sabonete apresentou uma acidez de 1,52 e a base glicerinada uma acidez de 1,01, tal diferença devese provavelmente ao aumento de ácidos graxos livres devido à adição de óleo de oliva. $\mathrm{O}$ pH do sabonete formulado foi igual a 10 .

Com relação a preferência dos consumidores pela essência realizou-se uma pesquisa com 84 provadores, no qual foram classificados por sexo, resultando em um total de 38 homens e 46 mulheres.

Tabela 2: Testes físico-químicos de controle de qualidade do sabonete

\begin{tabular}{ccccc}
\hline Composições & $\begin{array}{c}\text { Água } \\
\text { absorvida }\end{array}$ & $\begin{array}{c}\text { Resistência } \\
\text { à água \% }\end{array}$ & $\begin{array}{c}\text { Durabilidade \% } \\
\text { Sabonete }\end{array}$ & $\begin{array}{c}\text { Altura espuma } \\
\text { (mL) }\end{array}$ \\
\hline $\begin{array}{c}\text { Base glicerina- } \\
\text { da }\end{array}$ & $22,3 \pm 4,1$ & $77,7 \pm 4,1$ & $84,7 \pm 6,6$ & $42 \pm 7,1$ \\
\hline
\end{tabular}




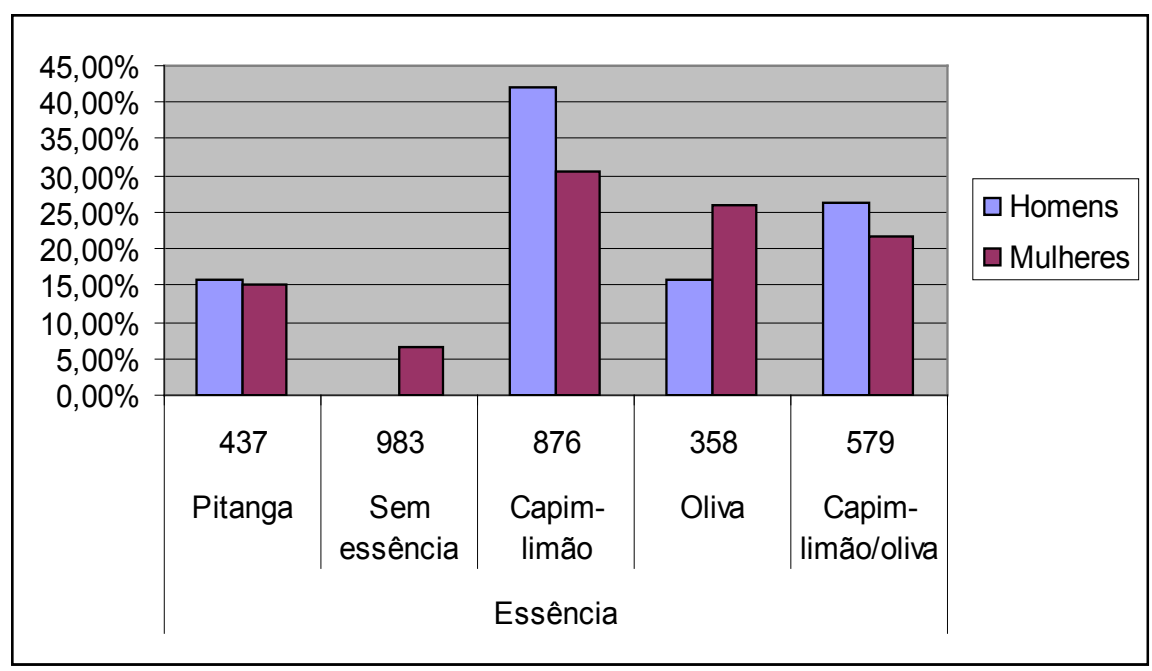

Figura 2. Percentual de preferência no teste afetivo

Entre os homens verificou-se à preferência para essência de capim-limão devido provavelmente ao seu aroma mais acentuado. Entre as mulheres houve uma variação entre as escolhas, mas a preferida também foi a de capim-limão.

\section{Conclusão}

Os resultados demonstraram que o caroço de azeitona oriundo do processamento de azeitonas, pode ser reaproveitado e incorporado como esfoliante na produção de sabonete. A adição do óleo de oliva ao sabonete pode ajudar na regeneração dos lipídeos da camada córnea, reestruturando a camada lipídica protetora, deixando a pele mais hidratada e com aspecto saudável. A caracterização físico-química do sabonete obtido revela que este foi formulado adequadamente, indicando a viabilidade de utilização do caroço residual na produção desse tipo de produto.

\section{Referências}

Associação Brasileira de Normas Técnicas - ABNT. Teste de comparação pareada em análise sensorial- NBR 13088. Rio de Janeiro: ABNT; 1994 b.

Arnau,A.M.G. Higiene cutánea: jabones y syndets.Actualidad Dermatologica, p.85-94, 1995.

Brasil. Ministério da Saúde. Agência Nacional de Vigilância Sanitária. RDC no 211. Dispõe sobre a definição e a classificação de produtos de higiene pessoal, cosméticos e perfumes. Brasília, 14 de julho de 2005.

Brasil. Agência Nacional de Vigilância Sanitária. Gerência Geral de cosméticos. Guia de Controle de Qualidade de Produtos Cosméticos: Uma abordagem sobre os Ensaios Físicos e Químicos. 2 ed. Brasília, 2008. 120 p.

EPAMIG, Empresa de Pesquisa Agropecuária de Minas Gerais, endereço disponível em: http://www.epamig.br/index.php?option=com content\&task=view\&id=1440 , acesso 14/11/2013.Faber J. Avanços na compreensão do paladar. Maring.v.11, n.1, p.14. 2006.

Farmacopéia Brasileira 5a. Ed., São Paulo: Organização Andrei Editora, 2010
Maia Campos, P. B. J. (2002). Desenvolvimento de produtos cosméticos. Cosmetics \& Toiletries, 14, 56-59.

Mohammadi, F., Czarnota, A., Harrison, J., \& Leonard, C. (2005).WIPO Patent No. 2005074509. Geneva, Switzerland: World Intellectual Property Organization.

Novak, A. C., Sydney, E. B., \& Soccol, C. R. (2014). Biocosmetics. InBiotransformation of Waste Biomass into High Value Biochemicals (pp. 389-411). Springer New York.

Oliveira, L. M. Benefícios comprovados de óleos brasileiros. Cosmetics \& Toiletries. v.15, n.5, p. 50-55, 2003

Prista, L. N.; Bahia, M. F. G.; Vilar, E. Dermofarmacia e Cosmética. Porto: Associação Nacional de Farmácia, 1995.

Rodríguez, G., Lama, A., Rodríguez, R., Jiménez, A., Guillén, R., \& Fernández-Bolanos, J. (2008). Olive stone an attractive source of bioactive and valuable compounds. Bioresource technology, 99(13), 5261-5269.

Silva, C. R. S. Biomimeticos com ativos da Amazônia. Cosmetics \& Toiletries. v. 15, n.5, p.66-71, 2003

Souza, V. B., \& Ferreira, J. R. (2010). Desenvolvimento e estudos de estabilidade de cremes e géis contendo sementes e extratos do bagaço da uva Isabel (Vitis labrusca L); . Rev. ciênc. farm. básica apl, 31(3) 